\title{
Involvement of Senescence and Mitochondrial Fission in Endothelial Cell Pro-Inflammatory Phenotype Induced by Angiotensin II
}

\author{
Masashi Miyao ${ }^{1,2}$, Stephanie Cicalese ${ }^{1}$, Tatsuo Kawai ${ }^{1}$, Hannah A. Cooper ${ }^{1}$, Michael J. Boyer ${ }^{1}$, \\ Katherine J. Elliott ${ }^{1}$, Steven J. Forrester ${ }^{1}$, Ryohei Kuroda ${ }^{1}$, Victor Rizzo ${ }^{1}$, Tomoki Hashimoto ${ }^{3, *}$, \\ Rosario Scalia ${ }^{1, *}$ and Satoru Eguchi $1, * \mathbb{C}$ \\ 1 Cardiovascular Research Center, Lewis Katz School of Medicine at Temple University, 3500 N. Broad Street, \\ Philadelphia, PA 19140, USA; miyaom@fp.med.kyoto-u.ac.jp (M.M.); tug51315@temple.edu (S.C.); \\ tuf88636@temple.edu (T.K.); tug05907@temple.edu (H.A.C.); tue89415@temple.edu (M.J.B.); \\ kelliott@temple.edu (K.J.E.); steven.forrester@emory.edu (S.J.F.); tun26594@temple.edu (R.K.); \\ rizzov@temple.edu (V.R.) \\ 2 Department of Forensic Medicine, Kyoto University Graduate School of Medicine, Yoshida-Konoe-cho, \\ Sakyoku, Kyoto 606-8501, Japan \\ 3 Department of Neurosurgery and Neurobiology, Barrow Aneurysm and AVM Research Center, \\ Barrow Neurological Institute, Phoenix, AZ 85013, USA \\ * Correspondence: tomoki.hashimoto@barrowneuro.org (T.H.); rscalia@temple.edu (R.S.); \\ seguchi@temple.edu (S.E.)
}

Received: 4 April 2020; Accepted: 26 April 2020; Published: 28 April 2020

\begin{abstract}
Angiotensin II (AngII) has a crucial role in cardiovascular pathologies, including endothelial inflammation and premature vascular aging. However, the precise molecular mechanism underlying aging-related endothelial inflammation induced by AngII remains elusive. Here, we have tested a hypothesis in cultured rat aortic endothelial cells (ECs) that the removal of AngII-induced senescent cells, preservation of proteostasis, or inhibition of mitochondrial fission attenuates the pro-inflammatory EC phenotype. AngII stimulation in ECs resulted in cellular senescence assessed by senescence-associated $\beta$ galactosidase activity. The number of $\beta$ galactosidase-positive ECs induced by AngII was attenuated by treatment with a senolytic drug ABT737 or the chemical chaperone 4-phenylbutyrate. Monocyte adhesion assay revealed that the pro-inflammatory phenotype in ECs induced by AngII was alleviated by these treatments. AngII stimulation also increased mitochondrial fission in ECs, which was mitigated by mitochondrial division inhibitor-1. Pretreatment with mitochondrial division inhibitor-1 attenuated AngII-induced senescence and monocyte adhesion in ECs. These findings suggest that mitochondrial fission and endoplasmic reticulum stress have causative roles in endothelial senescence-associated inflammatory phenotype induced by AngII exposure, thus providing potential therapeutic targets in age-related cardiovascular diseases.
\end{abstract}

Keywords: endothelial cells; angiotensin II; senolytic; ER stress; inflammation

\section{Introduction}

The vascular endothelium is critical to preserve vascular homeostasis, which includes tonus regulation, barrier function, and anti-coagulation. Thus, endothelial cells (ECs), which form the monolayer of vascular endothelium, are believed to protect against vascular pathology associated with hypertension as well as atherosclerosis, the two major causes for cardiovascular mortality [1,2]. However, ample evidence suggests that the disruption of EC homeostasis, termed endothelial dysfunction, is the predominant driving force for the development of these diseases in human as well 
as established animal models [1-3]. The phenotype of endothelial dysfunction is characterized by reduced vasodilation, disruption in barrier integrity, oxidative stress, and enhanced inflammatory responses. Specifically, the endothelial inflammatory responses involve increased cytokine and chemokine production as well as expression of cell adhesion molecules leading to recruitment of the activated leukocytes to the endothelium [1,2]. However, detailed molecular mechanisms causing the pro-inflammatory phenotype of the dysfunctional ECs are not fully explored, which hampers the development of specific medications to preserve endothelial function.

While renin angiotensin system (RAS) is a physiologically important endocrine system to maintain blood pressure and volume, systemic and local over-reactivity of this system significantly contributes to the development of cardiovascular diseases [4,5]. Accordingly, inhibitors of the RAS, including the antagonists for the angiotensin II type 1 receptor (AT1R), appear effective at protecting against endothelial dysfunction in clinical studies [6] as well as endothelial inflammation in preclinical studies [5,7]. Importantly, the endothelial inflammatory responses can be simulated in vitro with cultured ECs and angiotensin II (AngII) stimulation. Analyses utilizing cultured ECs have provided useful information about the signaling mechanism of EC inflammation via the AT1R stimulation $[5,8]$. One of the attractive mechanisms which appears to mediate the pro-inflammatory phenotype of ECs in response to AngII is mitochondrial dysfunction, such as an increase in the generation of reactive oxygen species (ROS) [9]. Analogous to endothelial dysfunction, mitochondrial dysfunction is associated with almost all types of cardiovascular disease $[10,11]$. Although the detailed molecular mechanism by which mitochondrial dysfunction occurs in ECs remains unclear, dysfunctional mitochondria in ECs are frequently associated with more fragmented structures caused by fission [12-14]. A GTPase Dynamin-related protein 1 (Drp1) is a master-regulator of mitochondrial fission [15]. It has been recently reported that AngII increases mitochondrial ROS production in cultured vascular smooth muscle cells (VSMCs), which was attenuated by a small molecule inhibitor of Drp1, mitochondrial division inhibitor-1 (mdivi1) [16]. However, limited information is available in ECs regarding the relationship among AngII, mitochondrial fission, and inflammation.

Aging is a nonmodifiable risk factor for almost all types of cardiovascular pathologies, including the development of endothelial dysfunction in humans [17]. Importantly, there are individuals in which accelerated vascular aging has been identified phenotypically, among the predisposed middle-aged populations [18]. However, the molecular mechanism of this prematurely occurring endothelial aging remains obscure. In young rodent models of AngII infusion, vascular cells were prematurely aged, as qualified through signatures of senescence, including increased senescence-associated $\beta$ galactosidase activity [19-21]. It should be noted that the premature cardiovascular aging induced by AngII is associated with disruption of proteostasis, causing endoplasmic reticulum (ER) stress and accumulation of protein aggregates [22-25]. Important to the present study, AngII stimulation in cultured aortic VSMCs or ECs recapitulates these senescent characteristics of the vasculature $[19,26]$.

In addition to its importance in organ development, senescence is considered as a primary protection mechanism to retard dysfunctional cell phenotypes in over-replicated or over-stressed cells to prevent cancer and apoptosis, respectively [27]. However, senescent cells are not entirely silent in cellular functions, and instead, they alter surrounding cells and tissues via production of specific paracrine factors termed senescence-associated secretory phenotype (SASP), which transmit a pro-inflammatory phenotype to surrounding non-senescent cells [28]. Accordingly, senescence and SASP have been implicated in vascular inflammatory diseases, including atherosclerosis, hypertension, and abdominal aortic aneurysms [29]. Elimination of senescent cells by drugs that cause selective apoptosis of senescent cells appears effective to prevent the development of atherosclerosis in a mouse model [30]. However, cell type-specific roles of senescence, such as those in endothelial inflammation, have not been sufficiently explored. 
According to the above literature suggesting the importance of the RAS, mitochondrial fission, and senescence in EC inflammation, we have tested a hypothesis in cultured aortic ECs that removal of senescent cells, preservation of proteostasis, or inhibition of mitochondrial fission attenuates the pro-inflammatory EC phenotype induced by AngII. Our findings support the role of mitochondrial fission and ER stress in mediating senescence and subsequent EC inflammation and thus suggest the need for further investigation of this novel cascade in animal models of cardiovascular diseases and in humans.

\section{Results}

\subsection{Induction of Senescence by AngII in ECs}

After stimulation with AngII for $48 \mathrm{~h}$, rat aortic ECs demonstrated an increase in senescence-associated $\beta$ galactosidase positive cells (Figure 1A,B). Stimulation with AngII did not significantly alter the attached cell numbers (Figure 1C). To verify that the $\beta$ galactosidase positive cells specifically represent senescent cell populations, rat aortic ECs were co-treated with a senolytic, ABT737, which specifically causes apoptosis of senescent cells [31], or its vehicle dimethyl sulfoxide (DMSO). Treatment with ABT737 almost completely attenuated $\beta$ galactosidase positive cell populations in ECs induced by the AngII stimulation (Figure 1D,E and Supplementary Figure S1a-c) supporting the specificity of the $\beta$ galactosidase staining as a marker of senescent ECs. The lack of decline in cell numbers in ABT737 treated ECs (Figure 1F) could be due to the pretreatment of senolytic on non-senescent ECs instead of post-treatment on existing senescent ECs.

AT1R has been implicated in the pathological functions of AngII, including the induction of senescence $[5,19]$. The disruption of proteostasis, including enhanced protein misfolding, is a potential mechanism by which AT1R mediates senescence [32]. To determine if increased protein misfolding is required for AngII-induced senescence, rat aortic ECs were pretreated with a chemical ER chaperone, 4-phenylbutyrate (4-PBA). Indeed, 4-PBA attenuated AngII induction of senescence in rat aortic ECs without altering the attached cell numbers (Figure 2A-C and Supplementary Figure S1d-f). 
A

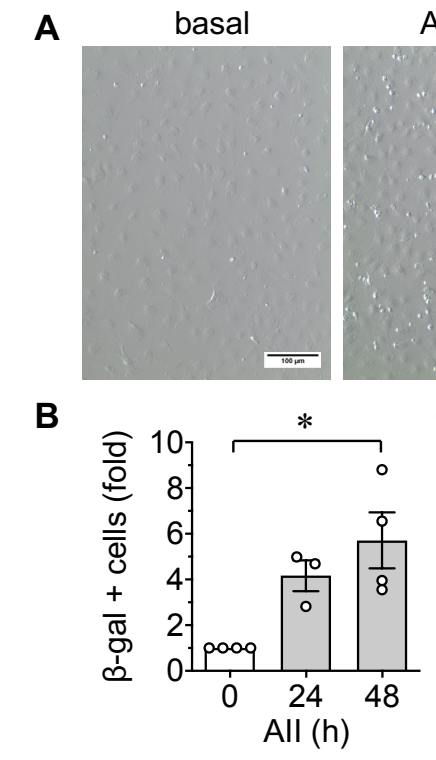

All 24h

All 48h
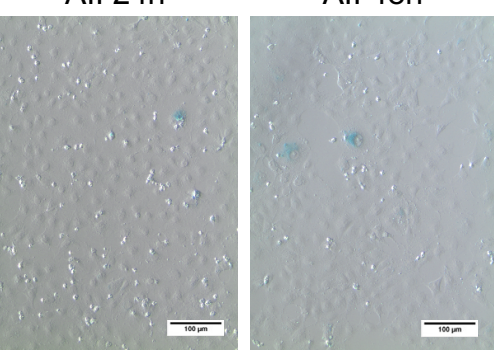

\section{C}

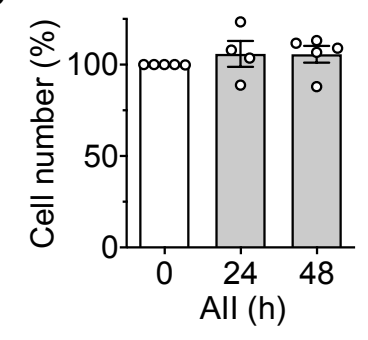

D

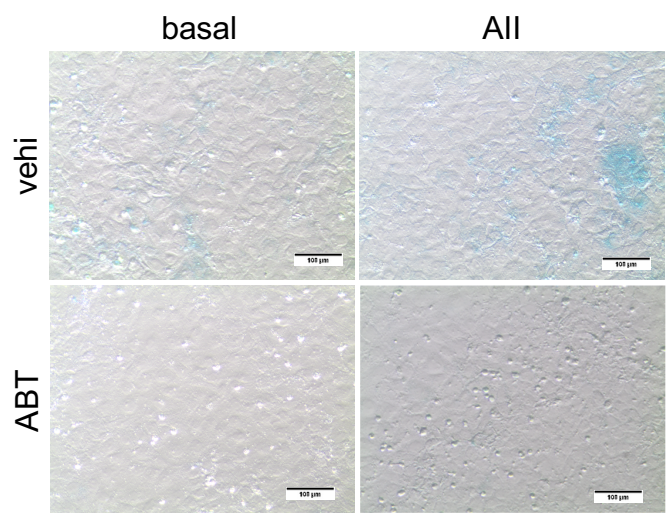

E

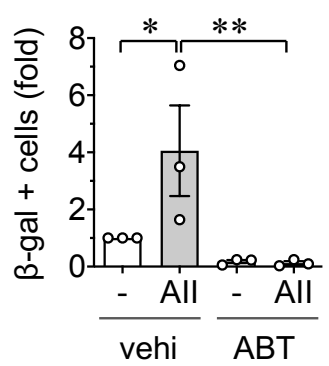

$\mathbf{F}$

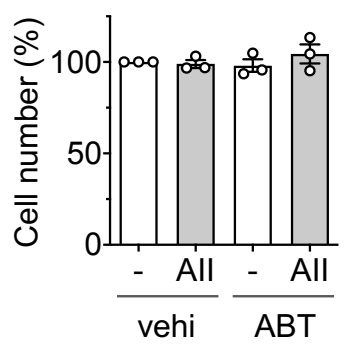

Figure 1. Induction of senescence by angiotensin II (AngII) in endothelial cells. (A-C) Cultured rat aortic endothelial cells (ECs) were serum-starved for $24 \mathrm{~h}$. ECs were stimulated with $100 \mathrm{nM}$ AngII (AII) for $24 \mathrm{~h}$ or $48 \mathrm{~h}$, as indicated. Representative staining data are shown (A). Scale bar indicates $100 \mu \mathrm{m}$. $\beta$ galactosidase positive cells (B) and total attached cells (C) per high power field (HPF) were counted for each group and expressed as fold basal or \% basal, respectively. The bars in the graphs show the mean \pm SEM from independent experiments $(\mathbf{B}, 0 \mathrm{~h} n=4,24 \mathrm{~h} n=3,48 \mathrm{~h} n=4, \mathrm{C}, 0 \mathrm{~h} n=5$, $24 \mathrm{~h} n=4,48 \mathrm{~h} n=5$ ). $0.54 \pm 0.37 \%$ were $\beta$ galactosidase positive in $0 \mathrm{~h}$ ECs. (D-F) ECs pretreated with a senolytic drug, ABT737 (ABT, $30 \mathrm{nM}$ ), or vehicle (vehi, 0.1\% DMSO final) for 30 min were stimulated with $100 \mathrm{nM}$ AngII (AII) for $48 \mathrm{~h}$. Representative staining data are shown (D). Scale bar indicates $100 \mu \mathrm{m}$. $\beta$ galactosidase positive cells (E) and total attached cells (F) were counted in each group and expressed as fold basal or \% basal, respectively. The bars in the graphs show the mean \pm SEM from three independent experiments. $1.69 \pm 1.20 \%$ were $\beta$ galactosidase positive in basal vehicle ECs. * indicates $p<0.05$. ${ }^{* *}$ indicates $p<0.01$. 
A

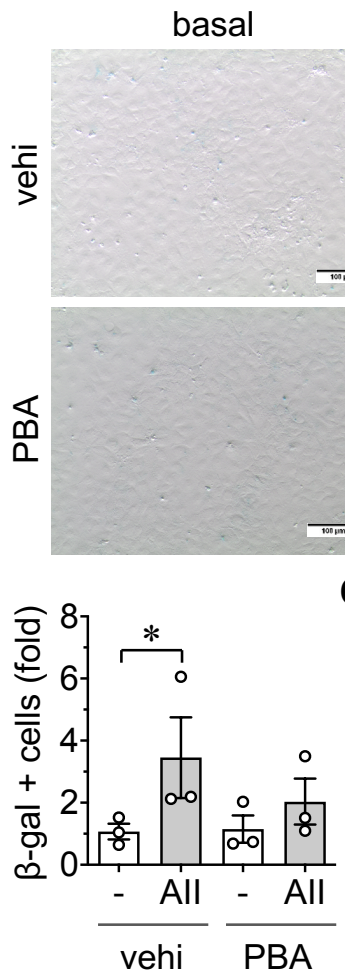

All

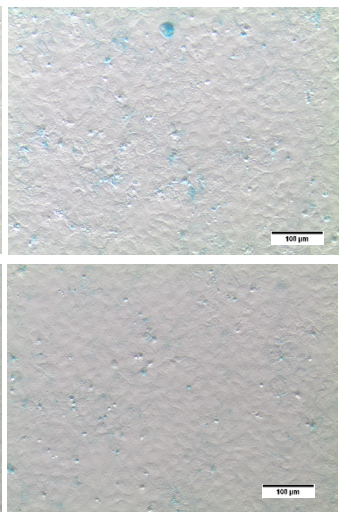

C

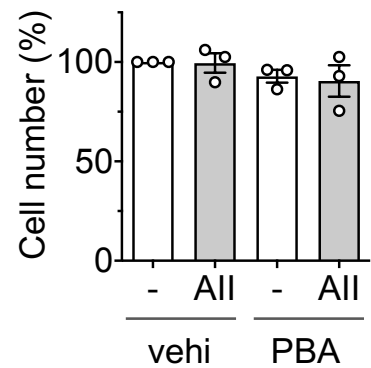

Figure 2. Chemical chaperone mitigates AngII-induced senescence. $(\mathbf{A}, \mathbf{B})$ Rat aortic ECs pretreated with chemical ER chaperone, 4-PBA (PBA, $1 \mathrm{mM}$ ), or vehicle (vehi, PBS $0.1 \%$ final) were stimulated with $100 \mathrm{nM}$ AngII (AII) for $48 \mathrm{~h}$. Representative staining data are shown (A). Scale bar indicates $100 \mu \mathrm{m}$. $\beta$ galactosidase positive cells (B) and total attached cells (C) were counted in each group and expressed as fold basal or \% basal, respectively. The bars in the graphs show the mean \pm SEM from three independent experiments. $1.07 \pm 0.44 \%$ were $\beta$ galactosidase positive in basal vehicle ECs. ** indicates $p<0.01$.

\subsection{Induction of Leukocyte Adhesion via ER stress and Senescence in ECS}

To assess if AngII induced EC senescence is accompanied by a pro-inflammatory EC phenotype, a THP-1 monocyte adhesion assay was performed. The stimulation of rat aortic ECs with AngII for $48 \mathrm{~h}$ significantly increased the adhesion of THP-1 cells. Pretreatment with the AT1R antagonist Olmesartan mitigated the adhesion response (Figure 3A,B and Supplementary Figure S1g-i), verifying that AT1R promotes a pro-inflammatory EC phenotype. As expected, 4-PBA, as well as ABT737, attenuated THP1 adhesion to ECs induced by AngII (Figure 3C-F) suggesting the regulatory roles of ER stress and premature EC senescence in the pathological endothelial inflammation. 
A

vehi

vehi+All

Olm
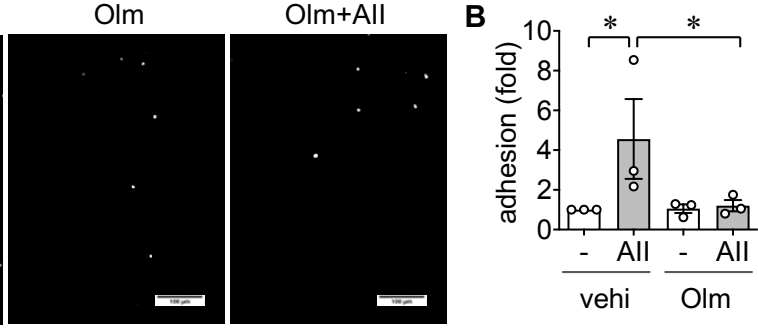

C

vehi

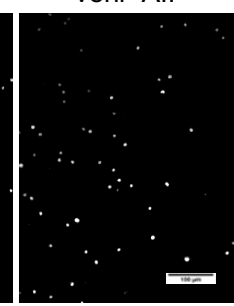

vehi+All
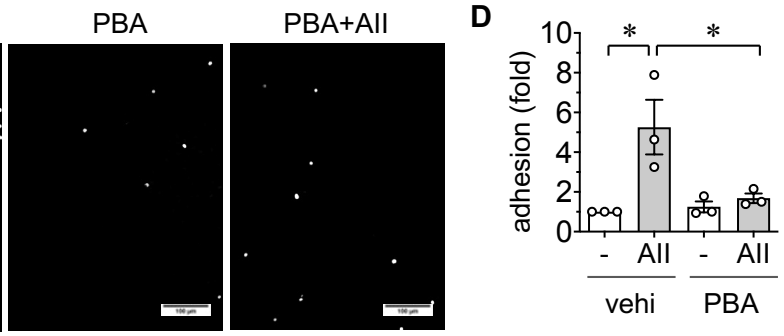

E

vehi

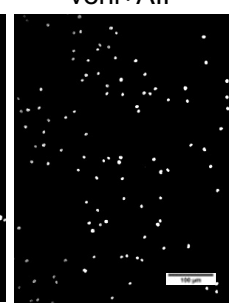

vehi+All
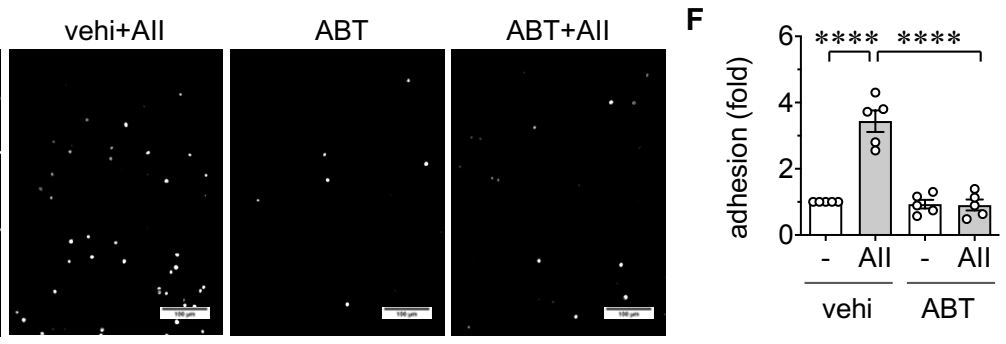

Figure 3. Involvement of angiotensin II type 1 (AT1) receptor, ER stress, and senescence in monocyte adhesion induced by angiotensin II in endothelial cells. (A,B) Serum starved rat aortic ECs pretreated with AT1R antagonist, Olmesartan (Olm, $10 \mu \mathrm{M}$ ) for 30 min were incubated with $100 \mathrm{nM}$ AngII (AII) for $48 \mathrm{~h}$. ECs were then incubated with THP-1 cells for $30 \mathrm{~min}$, washed, and adherent THP-1 cells were quantified. Representative staining data are shown (A). Scale bar indicates $100 \mu \mathrm{m}$. Attached THP-1 cells were counted in each group and expressed as fold basal (B). $7.7 \pm 2.9$ THP-1 cells were attached per HPF in basal vehicle ECs. (C,D) Serum starved ECs pretreated with $1 \mathrm{mM} 4$-PBA (PBA) for $30 \mathrm{~min}$ were incubated with $100 \mathrm{nM}$ AngII (AII) for $48 \mathrm{~h}$. ECs were then incubated with THP-1 cells for 30 min, washed, and adherent THP-1 cells were quantified. Representative staining data are shown (C). Scale bar indicates $100 \mu \mathrm{m}$. Attached THP-1 cells were counted in each group and expressed as fold basal (D). $14.4 \pm 10.9$ THP-1 cells were attached per HPF in basal vehicle ECs. (E,F) Serum starved ECs pretreated with ABT737 (ABT, $30 \mathrm{nM}$ ) or vehicle (vehi, $0.1 \%$ DMSO final) for $30 \mathrm{~min}$ were incubated with $100 \mathrm{nM}$ AngII (AII) for $48 \mathrm{~h}$. ECs were then incubated with THP-1 cells for $30 \mathrm{~min}$, washed, and adherent THP-1 cells were quantified. Representative staining data are shown (E). Scale bar indicates $100 \mu \mathrm{m}$. Attached THP-1 cells were counted in each group and expressed as fold basal (F). $5.7 \pm 3.3$ THP-1 cells were attached per HPF in basal vehicle ECs. The bars in the graphs show the mean \pm SEM from three-five independent experiments. ${ }^{*}$ indicates $p<0.05 .{ }^{* * * *}$ indicates $p<0.0001$.

\subsection{Role of Mitochondrial Fission in EC Senescence and Inflammation}

Mitochondrial fission is frequently seen in EC models of cardiovascular diseases and associated with mitochondrial dysfunction [12-14]. Additionally, the contribution of mitochondrial fission in EC senescence has been demonstrated [33]. Accordingly, mitochondrial fission was assessed using mitochondrial fragmentation count (MFC) with or without AngII stimulation for $3 \mathrm{~h}$ in rat aortic ECs. AngII stimulated mitochondrial fission in rat aortic ECs. Pretreatment with mdivi1, a pharmacological inhibitor of mitochondrial fission inducer Drp1 [34], attenuated mitochondrial fission induced by AngII (Figure 4A,B). While mdivi1 slightly decreased cell number when combined with AngII, pretreatment 
with mdivi1 also attenuated AngII-induced senescence and leukocyte adhesion in rat aortic ECs (Figure $4 \mathrm{C}-\mathrm{G}$ ) suggesting that mitochondrial fission contributes to an inflammatory aging phenotype in ECs.

A

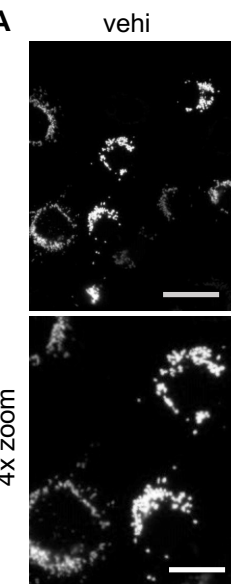

vehi+All

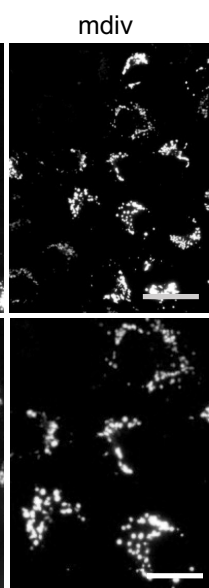

B
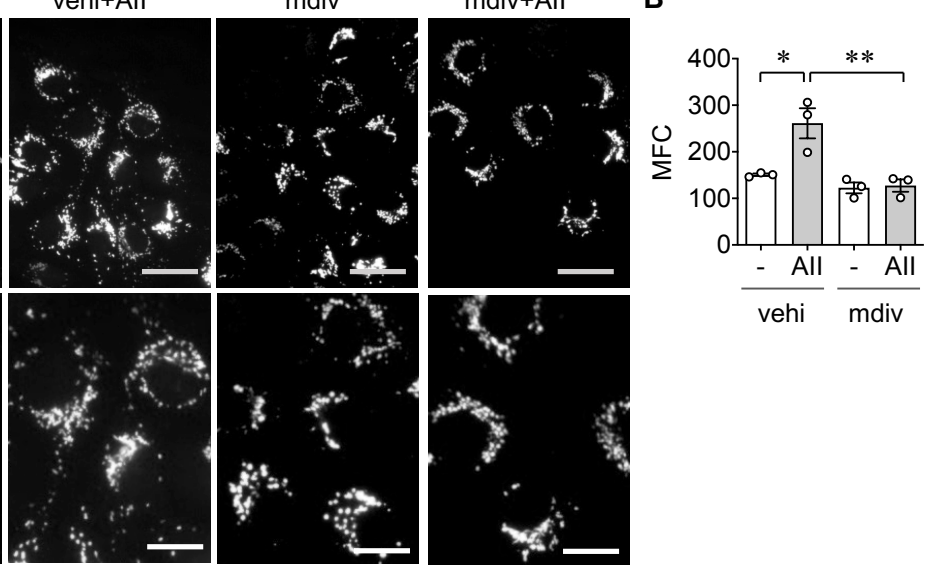

C

basal

All

D

E
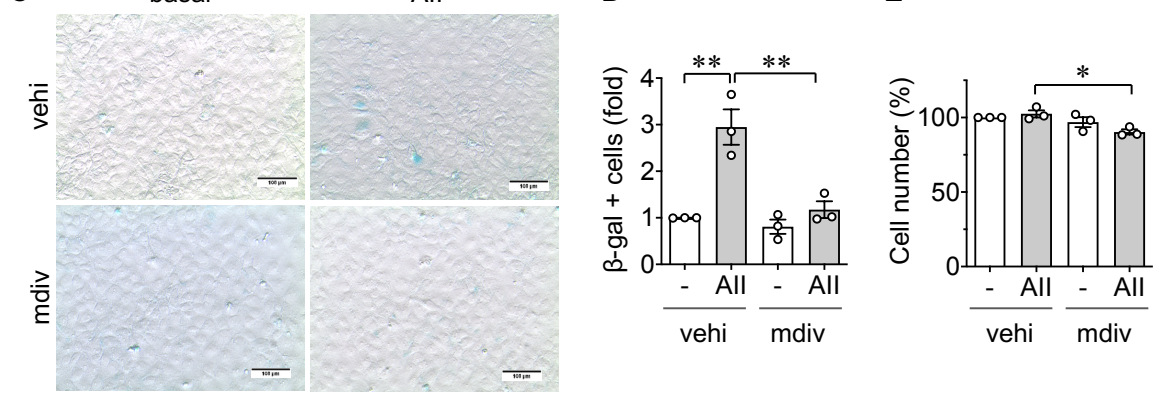

F

vehi

vehi+All
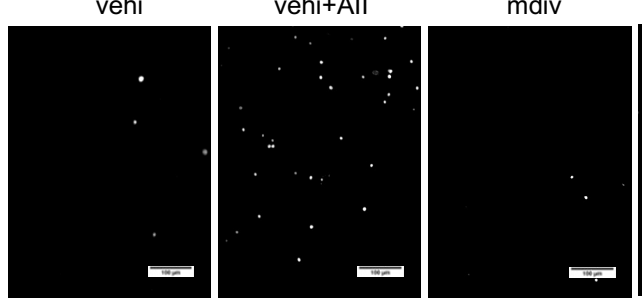

mdiv+All

G
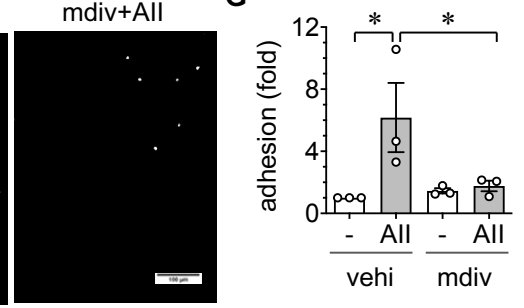

Figure 4. Upstream role of mitochondrial fission in endothelial cell senescence and inflammation induced by AngII. (A,B) Serum starved rat aortic ECs transduced with 10 moi adenovirus encoding mito-dsRed for $48 \mathrm{~h}$ and pretreated with mitochondrial fission inhibitor, mdivi1 (mdiv, $5 \mu \mathrm{M}$ ) or vehicle (vehi, DMSO $0.1 \%$ final) for $60 \mathrm{~min}$ were stimulated with $100 \mathrm{nM}$ AngII (AII) for $3 \mathrm{~h}$. Representative staining data are shown, and 4x zoomed pictures are included (A). Scale bar is $15 \mu \mathrm{m}$ and $7.5 \mu \mathrm{m}$ (zoom), respectively. Mitochondrial fission count (MFC) was measured (B). (C-E) Rat aortic ECs pretreated with mdivi1 (mdiv, $5 \mu \mathrm{M}$ ) or vehicle (vehi, DMSO, 0.1\% final) for 60 min were stimulated with $100 \mathrm{nM}$ AngII (AII) for $48 \mathrm{~h}$. Representative staining data are shown (C). Scale bar indicates $100 \mu \mathrm{m} . \beta$ galactosidase positive cells (D) and total attached cells (E) were counted in each group and expressed as fold basal or $\%$ basal, respectively. $0.48 \pm 0.17 \%$ were $\beta$ galactosidase positive in basal vehicle ECs. (F,G) Serum starved rat aortic ECs pretreated with mdivi1 (mdiv, $5 \mu \mathrm{M}$ ) or vehicle (vehi, DMSO $0.1 \%$ final) for $60 \mathrm{~min}$ were incubated with $100 \mathrm{nM}$ AngII (AII) for $48 \mathrm{~h}$. ECs were then incubated with THP-1 cells for $30 \mathrm{~min}$, washed, and adherent THP-1 cells were quantified. Representative staining data are shown (F). Scale bar indicates $100 \mu \mathrm{m}$. Attached THP-1 cells were counted in each group and expressed as fold basal (G). $14.8 \pm 10.1$ THP-1 cells were attached per HPF in basal vehicle ECs. The bars in the graphs show the mean \pm SEM from three independent experiments. ${ }^{*}$ indicates $p<0.05 .{ }^{*}$ indicates $p<0.01$. 


\section{Discussion}

In the present study, we have demonstrated that AngII induces mitochondrial fission and ER stress in ECs, contributing to EC senescence and pro-inflammatory phenotype (Figure 5). Thus, our data suggest mitochondrial fission as a unique target for therapy to combat aging-related cardiovascular diseases associated with chronic inflammatory conditions.

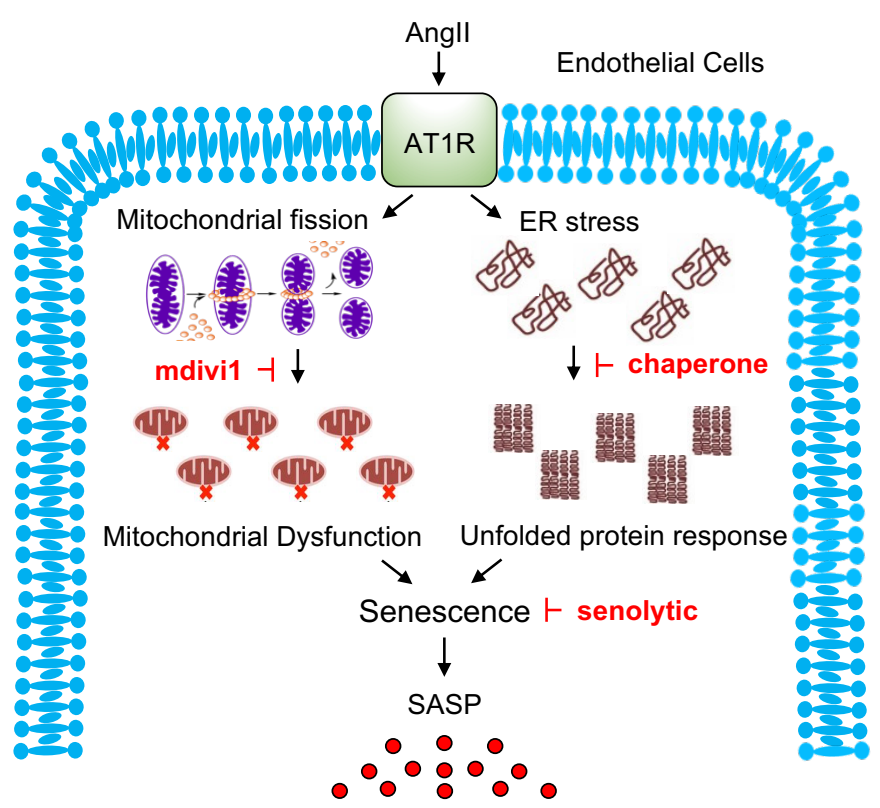

Endothelial pro-inflammatory phenotype

Figure 5. Proposed mechanisms of angiotensin II (AngII)-induced endothelial cell senescence and cardiovascular disease progression. AngII via AngII type 1 receptor (AT1R) induces mitochondrial fission and ER stress in ECs, which leads to EC senescence and inflammation. Inhibitors of mitochondrial fission and ER stress, as well as senolytics could be useful to prevent cardiovascular disease progression via inhibition of senescence-associated endothelial proinflammatory phenotype, including senescence-associated secretory phenotype (SASP).

Accumulating literature suggests the importance of VSMC senescence in AngII-related cardiovascular pathology [5,35]. However, the endothelial concept of AngII-mediated premature cardiovascular aging has been under-developed. Senescent cells actively produce pro-inflammatory cytokines known as SASP. Prior studies have shown the importance of EC SASP in aging related inflammation and cardiovascular pathology [36,37]. We further demonstrated that the elimination of senescent cells prevented leukocyte adhesion to ECs in the present study. As only a few percent of ECs become senescent upon AngII stimulation, it is likely that AngII promotes monocyte adhesion to ECs via SASP.

Endothelial ER stress and unfolded protein response (UPR) have been shown to contribute to atherosclerosis [38]. We and others have shown that AngII infusion caused vascular ER stress and that 4-PBA attenuated UPR and vascular remodeling in rodent models of AngII-induced hypertension [23,24]. The present study adds a role for AngII-induced ER stress in mediating EC senescence and inflammatory phenotype. In human umbilical vein ECs, inhibition of autophagy accelerated AngII-induced senescence [39], further supporting the disruption of proteostasis as a contributor to EC senescence. However, an increasing body of evidence suggests a potentially interdependent relationship between UPR and senescence [40]. Thus, it would be interesting to test if the prevention of senescent phenotype preserves proteostasis in ECs, such as those stimulated with AngII.

Prior studies have demonstrated that Drp1 likely mediates senescence through mitochondrial fission in cultured ECs [33] and cardiomyocytes [41]. Our data with mdivi1, together with these 
studies, suggest that mitochondrial fission is one potential mechanism by which AngII induces EC senescence. However, it should be noted that there is a statistically significant but slight decrease in EC numbers when comparing vehicle plus AngII to mdivi1 plus AngII. Since mdivi1 is known to act as a mitochondrial complex 1 inhibitor [42], it can be toxic to the cell when combined with AngII, which is a known inducer of mitochondrial ROS. Therefore, caution is prudent when considering the therapeutic utilization of mdivi1 as an anti-inflammatory and anti-aging reagent. Genetic approaches seem needed to clarify this issue in the future.

In human umbilical vein ECs, AngII causes senescence via activation of phosphatidyl-inositol 3 kinase [26]. A prior study also showed that Fos-related antigen 1 mediates AngII-induced senescence via induction of p16 $6^{\mathrm{INK} 4 \mathrm{~A}}$ in rat aortic ECs [43]. Thus, it is interesting to speculate on the upstream and downstream roles of phosphatidyl-inositol 3 kinase and Fos-related antigen 1 in Drp1 mediated mitochondrial fission and senescence in ECs under AngII activation, respectively. Regarding the signaling mechanism by which AngII elevates Drp1 activity and mitochondrial fission in ECs, it is likely that an upstream kinase phosphorylates and activates Drp1 in response to AT1R activation as demonstrated in VSMCs [16]. Alternatively, we have demonstrated that there is an inter-dependent relationship between Drp1 and the nuclear factor $\mathrm{k}-\mathrm{B}$ cascade in ECs, which mediates tumor necrosis factor $\alpha$-induced EC inflammation [44]. In VSMCs, mdivi1 attenuated AngII-induced THP-1 adhesion as well as enhanced oxygen consumption [45]. Thus, it would be interesting to explore the relationship between Drp1, the nuclear factor K-B cascade, and metabolic alterations in ECs upon AngII stimulation further. Lastly, the baseline and AngII-induced senescence seem exaggerated by passaging in some, but not all, experiments likely due to the combined effects of replicative senescence and stress (AngII)-induced premature senescence. Nonetheless, limited experimental $n$ numbers is one of the limitations of this study.

In conclusion, pharmacological protection against ER stress, as well as inhibition of mitochondrial fission, prevented senescence and enhancement of monocyte adhesion in ECs stimulated by AngII. Removal of senescent ECs by a senolytic also mitigated monocyte adhesion. These findings suggest the potential roles for mitochondrial fission and ER stress in mediating endothelial inflamm-aging phenotype upon AngII exposure.

\section{Materials and Methods}

\subsection{Cell Culture}

Primary aortic ECs (passage 4-8) derived from 6-8 week Sprague-Dawley rats purchased from Cell Biologics (RA-6052) were cultured in Dulbecco's modified Eagle's medium (DMEM) with $1 \mathrm{~g} / \mathrm{L}$ D-glucose, $1 \mathrm{mmol} / \mathrm{L}$ sodium pyruvate, $100 \mathrm{IU}$ penicillin, $100 \mu \mathrm{g} / \mathrm{mL}$ streptomycin, and $10 \%$ fetal bovine serum (FBS) supplementation. Approximately 80-90\% confluent cells serum-starved for $24 \mathrm{~h}$ on 12-well culture plates (growth area $3.8 \mathrm{~cm}^{2}$ ) were stimulated with AngII (100 nM) up to $48 \mathrm{~h}$. For the 48 stimulations, the AngII stimulation was repeated at the $24 \mathrm{~h}$ time point. For pharmacological intervention, cells serum-starved for $24 \mathrm{~h}$ were incubated with fresh DMEM for $1 \mathrm{~h}$, then pre-treated with indicated drugs or vehicle controls prior to stimulation with AngII. Pilot experiments in ECs with AngII stimulation $(0,1,3,6,24$, and $48 \mathrm{~h}$ time points) demonstrated that maximal mitochondrial fission induced by AngII occurred at $3 \mathrm{~h}$, whereas consistent induction of THP- 1 adhesion and senescence required $48 \mathrm{~h}$ stimulation with AngII, which set the time points in these assays. Key reagents and resources used in cell culture studies were described in Supplementary Table S1.

\subsection{Senescence-Associated $\beta$ Galactosidase Assay}

Senescence-associated $\beta$ galactosidase activity was measured using the X-Gal staining system (Goldbio). In 12-well plates (growth area $3.8 \mathrm{~cm}^{2}$ ), at least 2 wells were assigned for each experimental condition. Upon AngII stimulation for $48 \mathrm{~h}$, ECs were fixed with a $4 \%$ paraformaldehyde solution (Electron Microscopy Sciences) in phosphate-buffered saline (PBS) for $10 \mathrm{~min}$, washed with Hanks 
Balanced Salt solution (HBSS) four times for $10 \mathrm{~min}$, and incubated with $40 \mathrm{mM}$ phosphate buffer containing $1 \mathrm{mg} / \mathrm{mL}$ X-Gal in $150 \mathrm{mM} \mathrm{NaCl}, 2 \mathrm{mM} \mathrm{MgCl}_{2}, 5 \mathrm{mM} \mathrm{K}_{3} \mathrm{Fe}(\mathrm{CN})_{6}$, and $5 \mathrm{mM} \mathrm{K}_{4} \mathrm{Fe}(\mathrm{CN})_{6}$ at $37^{\circ} \mathrm{C}$ for $12 \mathrm{~h}$. Cells were washed twice with HBSS containing calcium and magnesium, and counter stained with Hoescht33342 (ThermoFisher, Waltham, MA, USA) for 5 min to stain nuclei. EC cultures were examined at $10 \times$ magnification to identify $\beta$ galactosidase positive cells. Only blue-stained cell(s) clearly surrounded by the non-stained cell membrane structure were counted as positive cells. While the examiners were not blinded from the conditions, $\beta$ galactosidase positive cells were counted in 5 randomly selected high-power fields (HPF) per condition and values were expressed as fold difference from 3-4 independent experiments (Figures 1, 2 and 4) or as percent difference in each experiment (Supplementary Figures) of positive cells versus total cell number. Total cell numbers were also demonstrated per condition in Figure 1, Figure 2, and Figure 4 as percent difference to the basal control conditions.

\subsection{Leukocyte Adhesion Assay}

To observe leukocyte attachment to ECs, THP-1 adhesion assay was performed, as described [5]. THP-1 monocytes (American Type Culture Collection) cultured in Roswell Park Memorial Institute/RPMI 1640 medium with $10 \%$ FBS, penicillin, and streptomycin were suspended in serum-free DMEM with $0.2 \%$ BSA and $5 \mu \mathrm{g} / \mathrm{mL}$ Hoechst 33342 for $30 \mathrm{~min}$ at $37^{\circ} \mathrm{C}$. These cells $\left(10^{4}\right.$ cells per $\left.\mathrm{cm}^{2}\right)$ were then applied to EC cultures on 24-well plates (growth area $1.9 \mathrm{~cm}^{2}$ ) for $30 \mathrm{~min}$ at $37^{\circ} \mathrm{C}$. EC cultures were then washed in PBS once for $5 \mathrm{~min}$ to remove unattached cells and subsequently imaged using a fluorescent inverted microscope. Stained THP-1 nuclei were counted to quantify adhesion to ECs as follows. Four wells were assigned for each experimental condition. Five randomly selected HPFs were captured per condition using a 10× objective lens. Images were imported into ImageJ, where the image was processed for background subtraction and conversion to a binary image followed by an analysis of particle count per visual field. Data were reported as fold difference to the control baseline mean value and compared across groups.

\subsection{Mitochondrial Morphology Analysis}

ECs were cultured on coverslips (growth area $2.54 \mathrm{~cm}^{2}$ ) fit on 12 -well plates. Cells were infected with 10 moi adenovirus encoding mito-dsRed for $48 \mathrm{~h}$ prior to the treatment with the inhibitors and AngII. Upon AngII treatment for $3 \mathrm{~h}$, ECs were washed twice for 5 min with DMEM and fixed in $3.7 \%$ paraformaldehyde for $15 \mathrm{~min}$ at $37^{\circ} \mathrm{C}$. Cells were then washed 3 times for $2 \mathrm{~min}$ with PBS and permeabilized with $0.2 \%$ Triton X-100 (Sigma T8787, Sigma, Saint Louis, MO, USA) in PBS for $10 \mathrm{~min}$. Cells were washed 3 times for $2 \mathrm{~min}$ in PBS and mounted on glass slides with ProLong Gold Antifade (Thermo Fisher P36931). Fluorescent signals were detected on a $60 \times$ oil objective lens with a 1.5 $\times$ adjustment attached to Olympus IX81 inverted fluorescent microscope with a Photometrics Cool SNAP HQ camera. Images were acquired using Metamorph software and imported into ImageJ, processed using iterative deconvolution, followed by rolling ball background subtraction and conversion to a color image for analysis using the Mito-Morphology plugin 5. The mitochondrial fission count (MFC) is defined as the number of mitochondria per cell (numerator) divided by the total mitochondrial area (pixels) of a given cell (denominator). Increasing MFC correlates to more mitochondria per given area, suggesting increased fission. Three wells were assigned for each experimental condition. Five randomly selected HPFs were captured per condition. In total, 3 independent experiments were used for analysis.

\subsection{Statistical Analysis}

Data are presented as mean \pm SEM. Comparisons were performed via $t$-test for 2 groups, or via 1-way ANOVA with the post hoc Tukey method for multiple groups using Prism software (GraphPad, San Diego, CA, USA). Differences were considered statistically significant at $p<0.05$. 
Supplementary Materials: The following are available online at http://www.mdpi.com/1422-0067/21/9/3112/s1, Figure S1: Effects of ABT737 and 4-PBA on AngII-induced EC senescence and effect of Olmesartan on AngII-induced THP-1 cell adhesion to ECs, Table S1: Key Reagents.

Author Contributions: M.M., S.C., S.J.F., V.R., R.S., and S.E. designed the study. M.M., S.C., S.J.F., T.K., H.A.C., M.J.B., and R.K. performed the experiments. M.M., S.C., and S.E. analyzed the data. M.M., S.C., K.J.E., T.H., R.S., and S.E. wrote the manuscript. All authors have read and agreed to the published version of the manuscript.

Funding: This study was supported by National Institute of Health grants, HL128324 (S.E. and V.R.), HL133248 (S.E.), DK111042 (R.S. and S.E.), NS109382 (S.E. and T.H.), NS109584 (T.H.), F31HL127971 (S.J.F.), F31HL146081 (M.J.B.), and F30HL146006 (H.A.C.), and a Japan Society for the Promotion of Science grant, Grant-in-Aid for Scientific Research 18KK0437 (M.M.).

Acknowledgments: The authors gratefully acknowledge Kunie Eguchi for her technical assistance.

Conflicts of Interest: The authors declare no conflict of interest.

\section{Abbreviations}

$\begin{array}{ll}\text { AngII } & \text { Angiotensin II } \\ \text { AT1R } & \text { Angiotensin II type 1 receptor } \\ \text { DMEM } & \text { Dulbecco's Modified Eagle's Medium } \\ \text { DMSO } & \text { Dimethyl sulfoxide } \\ \text { Drp1 } & \text { Dynamin-related protein 1 } \\ \text { ECs } & \text { Endothelial cells } \\ \text { ER } & \text { Endoplasmic reticulum } \\ \text { FBS } & \text { Fetal bovine serum } \\ \text { HPF } & \text { High power field } \\ \text { Mdivi1 } & \text { Mitochondrial division inhibitor-1 } \\ \text { MFC } & \text { Mitochondrial fragmentation count } \\ \text { PBS } & \text { Phosphate buffered saline } \\ \text { 4-PBA } & \text { 4-Phenylbutyrate } \\ \text { RAS } & \text { Renin angiotensin system } \\ \text { ROS } & \text { Reactive oxygen species } \\ \text { SASP } & \text { Senescence associated secretory phenotype } \\ \text { UPR } & \text { Unfolded protein response } \\ \text { VSMCs } & \text { Vascular smooth muscle cells }\end{array}$

\section{References}

1. Brandes, R.P. Endothelial dysfunction and hypertension. Hypertension 2014, 64, 924-928. [CrossRef]

2. Daiber, A.; Steven, S.; Weber, A.; Shuvaev, V.V.; Muzykantov, V.R.; Laher, I.; Li, H.; Lamas, S.; Munzel, T. Targeting vascular (endothelial) dysfunction. Br. J. Pharmacol. 2017, 174, 1591-1619. [CrossRef]

3. Widmer, R.J.; Lerman, A. Endothelial dysfunction and cardiovascular disease. Glob. Cardiol. Sci. Pract. 2014, 2014, 291-308. [CrossRef] [PubMed]

4. Wu, C.H.; Mohammadmoradi, S.; Chen, J.Z.; Sawada, H.; Daugherty, A.; Lu, H.S. Renin-Angiotensin System and Cardiovascular Functions. Arterioscler. Thromb. Vasc. Biol. 2018, 38, e108-e116. [CrossRef] [PubMed]

5. Forrester, S.J.; Booz, G.W.; Sigmund, C.D.; Coffman, T.M.; Kawai, T.; Rizzo, V.; Scalia, R.; Eguchi, S. Angiotensin II Signal Transduction: An Update on Mechanisms of Physiology and Pathophysiology. Physiol. Rev. 2018, 98, 1627-1738. [CrossRef] [PubMed]

6. Matsuzawa, Y.; Guddeti, R.R.; Kwon, T.G.; Lerman, L.O.; Lerman, A. Treating coronary disease and the impact of endothelial dysfunction. Prog. Cardiovasc. Dis. 2015, 57, 431-442. [CrossRef]

7. Brasier, A.R.; Recinos, A.; Eledrisi, M.S. Vascular inflammation and the renin-angiotensin system. Arterioscler. Thromb. Vasc. Biol. 2002, 22, 1257-1266. [CrossRef]

8. Higuchi, S.; Ohtsu, H.; Suzuki, H.; Shirai, H.; Frank, G.D.; Eguchi, S. Angiotensin II signal transduction through the AT1 receptor: Novel insights into mechanisms and pathophysiology. Clin. Sci. 2007, 112, 417-428. [CrossRef] 
9. Dikalov, S.I.; Nazarewicz, R.R. Angiotensin II-induced production of mitochondrial reactive oxygen species: Potential mechanisms and relevance for cardiovascular disease. Antioxid. Redox Signal. 2013, 19, 1085-1094. [CrossRef]

10. Murphy, E.; Ardehali, H.; Balaban, R.S.; DiLisa, F.; Dorn, G.W., 2nd; Kitsis, R.N.; Otsu, K.; Ping, P.; Rizzuto, R.; Sack, M.N.; et al. Mitochondrial Function, Biology, and Role in Disease: A Scientific Statement From the American Heart Association. Circ. Res. 2016, 118, 1960-1991. [CrossRef]

11. Siasos, G.; Tsigkou, V.; Kosmopoulos, M.; Theodosiadis, D.; Simantiris, S.; Tagkou, N.M.; Tsimpiktsioglou, A.; Stampouloglou, P.K.; Oikonomou, E.; Mourouzis, K.; et al. Mitochondria and cardiovascular diseases-from pathophysiology to treatment. Ann. Transl. Med. 2018, 6, 256. [CrossRef] [PubMed]

12. Shenouda, S.M.; Widlansky, M.E.; Chen, K.; Xu, G.; Holbrook, M.; Tabit, C.E.; Hamburg, N.M.; Frame, A.A.; Caiano, T.L.; Kluge, M.A.; et al. Altered mitochondrial dynamics contributes to endothelial dysfunction in diabetes mellitus. Circulation 2011, 124, 444-453. [CrossRef] [PubMed]

13. Diebold, I.; Hennigs, J.K.; Miyagawa, K.; Li, C.G.; Nickel, N.P.; Kaschwich, M.; Cao, A.; Wang, L.; Reddy, S.; Chen, P.I.; et al. BMPR2 preserves mitochondrial function and DNA during reoxygenation to promote endothelial cell survival and reverse pulmonary hypertension. Cell Metab. 2015, 21, 596-608. [CrossRef] [PubMed]

14. Wang, W.; Wang, Y.; Long, J.; Wang, J.; Haudek, S.B.; Overbeek, P.; Chang, B.H.; Schumacker, P.T.; Danesh, F.R. Mitochondrial fission triggered by hyperglycemia is mediated by ROCK1 activation in podocytes and endothelial cells. Cell Metab. 2012, 15, 186-200. [CrossRef] [PubMed]

15. Pagliuso, A.; Cossart, P.; Stavru, F. The ever-growing complexity of the mitochondrial fission machinery. Cell. Mol. Life Sci. 2018, 75, 355-374. [CrossRef] [PubMed]

16. Lim, S.; Lee, S.Y.; Seo, H.H.; Ham, O.; Lee, C.; Park, J.H.; Lee, J.; Seung, M.; Yun, I.; Han, S.M.; et al. Regulation of mitochondrial morphology by positive feedback interaction between PKCdelta and Drp1 in vascular smooth muscle cell. J. Cell. Biochem. 2015, 116, 648-660. [CrossRef]

17. Seals, D.R.; Jablonski, K.L.; Donato, A.J. Aging and vascular endothelial function in humans. Clin. Sci. 2011, 120, 357-375. [CrossRef]

18. Laurent, S.; Boutouyrie, P.; Cunha, P.G.; Lacolley, P.; Nilsson, P.M. Concept of Extremes in Vascular Aging. Hypertension 2019, 74, 218-228. [CrossRef]

19. Kunieda, T.; Minamino, T.; Nishi, J.; Tateno, K.; Oyama, T.; Katsuno, T.; Miyauchi, H.; Orimo, M.; Okada, S.; Takamura, M.; et al. Angiotensin II induces premature senescence of vascular smooth muscle cells and accelerates the development of atherosclerosis via a p21-dependent pathway. Circulation 2006, 114, 953-960. [CrossRef]

20. Xiong, S.; Salazar, G.; Patrushev, N.; Ma, M.; Forouzandeh, F.; Hilenski, L.; Alexander, R.W. Peroxisome proliferator-activated receptor gamma coactivator-1alpha is a central negative regulator of vascular senescence. Arterioscler. Thromb. Vasc. Biol. 2013, 33, 988-998. [CrossRef]

21. Chen, H.Z.; Wang, F.; Gao, P.; Pei, J.F.; Liu, Y.; Xu, T.T.; Tang, X.; Fu, W.Y.; Lu, J.; Yan, Y.F.; et al. Age-Associated Sirtuin 1 Reduction in Vascular Smooth Muscle Links Vascular Senescence and Inflammation to Abdominal Aortic Aneurysm. Circ. Res. 2016, 119, 1076-1088. [CrossRef]

22. Liang, B.; Wang, S.; Wang, Q.; Zhang, W.; Viollet, B.; Zhu, Y.; Zou, M.H. Aberrant endoplasmic reticulum stress in vascular smooth muscle increases vascular contractility and blood pressure in mice deficient of AMP-activated protein kinase- $\alpha 2$ in vivo. Arterioscler. Thromb. Vasc. Biol. 2013, 33, 595-604. [CrossRef] [PubMed]

23. Spitler, K.M.; Webb, R.C. Endoplasmic reticulum stress contributes to aortic stiffening via proapoptotic and fibrotic signaling mechanisms. Hypertension 2014, 63, e40-e45. [CrossRef] [PubMed]

24. Takayanagi, T.; Kawai, T.; Forrester, S.J.; Obama, T.; Tsuji, T.; Fukuda, Y.; Elliott, K.J.; Tilley, D.G.; Davisson, R.L.; Park, J.Y.; et al. Role of epidermal growth factor receptor and endoplasmic reticulum stress in vascular remodeling induced by angiotensin II. Hypertension 2015, 65, 1349-1355. [CrossRef]

25. Ayyadevara, S.; Mercanti, F.; Wang, X.; Mackintosh, S.G.; Tackett, A.J.; Prayaga, S.V.; Romeo, F.; Shmookler Reis, R.J.; Mehta, J.L. Age- and Hypertension-Associated Protein Aggregates in Mouse Heart Have Similar Proteomic Profiles. Hypertension 2016, 67, 1006-1013. [CrossRef] [PubMed]

26. Li, P.; Guo, X.; Lei, P.; Shi, S.; Luo, S.; Cheng, X. PI3K/Akt/uncoupling protein 2 signaling pathway may be involved in cell senescence and apoptosis induced by angiotensin II in human vascular endothelial cells. Mol. Biol. Rep. 2014, 41, 6931-6937. [CrossRef] 
27. van Deursen, J.M. The role of senescent cells in ageing. Nature 2014, 509, 439-446. [CrossRef]

28. Tchkonia, T.; Zhu, Y.; van Deursen, J.; Campisi, J.; Kirkland, J.L. Cellular senescence and the senescent secretory phenotype: Therapeutic opportunities. J. Clin. Investig. 2013, 123, 966-972. [CrossRef]

29. Mistriotis, P.; Andreadis, S.T. Vascular aging: Molecular mechanisms and potential treatments for vascular rejuvenation. Ageing Res. Rev. 2017, 37, 94-116. [CrossRef]

30. Childs, B.G.; Baker, D.J.; Wijshake, T.; Conover, C.A.; Campisi, J.; van Deursen, J.M. Senescent intimal foam cells are deleterious at all stages of atherosclerosis. Science 2016, 354, 472-477. [CrossRef]

31. Yosef, R.; Pilpel, N.; Tokarsky-Amiel, R.; Biran, A.; Ovadya, Y.; Cohen, S.; Vadai, E.; Dassa, L.; Shahar, E.; Condiotti, R.; et al. Directed elimination of senescent cells by inhibition of BCL-W and BCL-XL. Nat. Commun. 2016, 7, 11190. [CrossRef]

32. Cooper, H.A.; Scalia, R.; Rizzo, V.; Eguchi, S. Angiotensin II- and Alzheimer-Type Cardiovascular Aging. Circ. Res. 2018, 123, 651-653. [CrossRef] [PubMed]

33. Kim, Y.M.; Youn, S.W.; Sudhahar, V.; Das, A.; Chandhri, R.; Cuervo Grajal, H.; Kweon, J.; Leanhart, S.; He, L.; Toth, P.T.; et al. Redox Regulation of Mitochondrial Fission Protein Drp1 by Protein Disulfide Isomerase Limits Endothelial Senescence. Cell Rep. 2018, 23, 3565-3578. [CrossRef] [PubMed]

34. Smith, G.; Gallo, G. To mdivi-1 or not to mdivi-1: Is that the question? Dev. Neurobiol. 2017, 77, 1260-1268. [CrossRef] [PubMed]

35. Salazar, G. NADPH Oxidases and Mitochondria in Vascular Senescence. Int. J. Mol. Sci. 2018, $19,1327$. [CrossRef]

36. Prattichizzo, F.; Bonafe, M.; Ceka, A.; Giuliani, A.; Rippo, M.R.; Re, M.; Antonicelli, R.; Procopio, A.D.; Olivieri, F. Endothelial Cell Senescence and Inflammaging: MicroRNAs as Biomarkers and Innovative Therapeutic Tools. Curr. Drug Targets 2016, 17, 388-397. [CrossRef]

37. Kotla, S.; Le, N.T.; Vu, H.T.; Ko, K.A.; Gi, Y.J.; Thomas, T.N.; Giancursio, C.; Lusis, A.J.; Cooke, J.P.; Fujiwara, K.; et al. Endothelial senescence-associated secretory phenotype (SASP) is regulated by Makorin-1 ubiquitin E3 ligase. Metabolism 2019, 100, 153962. [CrossRef]

38. Civelek, M.; Manduchi, E.; Riley, R.J.; Stoeckert, C.J., Jr.; Davies, P.F. Chronic endoplasmic reticulum stress activates unfolded protein response in arterial endothelium in regions of susceptibility to atherosclerosis. Circ. Res. 2009, 105, 453-461. [CrossRef]

39. Chen, F.; Chen, B.; Xiao, F.Q.; Wu, Y.T.; Wang, R.H.; Sun, Z.W.; Fu, G.S.; Mou, Y.; Tao, W.; Hu, X.S.; et al. Autophagy protects against senescence and apoptosis via the RAS-mitochondria in high-glucose-induced endothelial cells. Cell. Physiol. Biochem. 2014, 33, 1058-1074. [CrossRef]

40. Pluquet, O.; Pourtier, A.; Abbadie, C. The unfolded protein response and cellular senescence. A review in the theme: Cellular mechanisms of endoplasmic reticulum stress signaling in health and disease. Am. J. Physiol. Cell Physiol. 2015, 308, C415-C425. [CrossRef]

41. Nishimura, A.; Shimauchi, T.; Tanaka, T.; Shimoda, K.; Toyama, T.; Kitajima, N.; Ishikawa, T.; Shindo, N.; Numaga-Tomita, T.; Yasuda, S.; et al. Hypoxia-induced interaction of filamin with Drp1 causes mitochondrial hyperfission-associated myocardial senescence. Sci. Signal. 2018, 11, eaat5185. [CrossRef] [PubMed]

42. Bordt, E.A.; Clerc, P.; Roelofs, B.A.; Saladino, A.J.; Tretter, L.; Adam-Vizi, V.; Cherok, E.; Khalil, A.; Yadava, N.; Ge, S.X.; et al. The Putative Drp1 Inhibitor mdivi-1 is a Reversible Mitochondrial Complex I Inhibitor that Modulates Reactive Oxygen Species. Dev. Cell 2017, 40, 583-594. [CrossRef] [PubMed]

43. Yang, D.; Xiao, C.; Long, F.; Wu, W.; Huang, M.; Qu, L.; Liu, X.; Zhu, Y. Fra-1 plays a critical role in angiotensin II-induced vascular senescence. FASEB J. 2019, 33, 7603-7614. [CrossRef] [PubMed]

44. Forrester, S.J.; Preston, K.J.; Cooper, H.A.; Boyer, M.J.; Escoto, K.M.; Poltronetti, A.J.; Elliott, K.J.; Kuroda, R.; Miyao, M.; Sesaki, H.; et al. Mitochondrial fission mediates endothelial inflammation. Hypertension 2020, in press.

45. Cooper, H.A.; Cicalese, S.; Preston, K.J.; Kawai, T.; Okuno, K.; Choi, E.T.; Kasahara, K.; Uchida, H.A.; Otaka, N.; Scalia, R.; et al. Targeting mitochondrial fission as a potential therapeutic for abdominal aortic aneurysm. Cardiovasc. Res. 2020, in press.

(C) 2020 by the authors. Licensee MDPI, Basel, Switzerland. This article is an open access article distributed under the terms and conditions of the Creative Commons Attribution (CC BY) license (http://creativecommons.org/licenses/by/4.0/). 